\title{
Reference values of respiratory impedance with impulse oscillometry in healthy Chinese adults
}

\author{
Xiao-Lin Liang', Yi Gao ${ }^{1}$, Wei-Jie Guan ${ }^{1}$, Jing $\mathrm{Du}^{2}$, Li Chen ${ }^{3}$, Wen Han ${ }^{4}$, Jin-Ming Liu ${ }^{5}$, Yong Lu ${ }^{6}$, \\ Yi Peng ${ }^{7}$, Bing-Rong Zhao ${ }^{8}$, Tao Wang ${ }^{9}$, Jin-Ping Zheng ${ }^{1}$
}

${ }^{1}$ National Clinical Research Center for Respiratory Disease, State Key Laboratory of Respiratory Disease, Guangzhou Institute of Respiratory Health, First Affiliated Hospital of Guangzhou Medical University, Guangzhou, China; ${ }^{2}$ Department of Respiratory and Critical Care, West China Hospital, Sichuan University, Chengdu, China; ${ }^{3}$ Department of Respiratory Medicine, The First Affiliated Hospital of Fujian Medical University, Fuzhou, China; ${ }^{4}$ Department of Respiratory and Critical Care Medicine, Shanxi Bethune Hospital, Shanxi Academy of Medical Sciences, Tongji Shanxi Hospital, Third Hospital of Shanxi Medical University, Taiyuan, China; ${ }^{5}$ Department of Pulmonary Function Test, Shanghai Pulmonary Hospital, Tongji University School of Medicine, Shanghai, China; ${ }^{6}$ Department of Respiratory and Critical Care Medicine, Beijing Institute of Respiratory Medicine and Beijing Chao-Yang Hospital, Capital Medical University, Beijing, China; ${ }^{7}$ Department of Respiratory Medicine, Union Hospital of Tongji Medical College, Huazhong University of Science and Technology, Wuhan, China; ${ }^{8}$ Department of Respiratory Medicine, National Key Clinical Specialty, Branch of National Clinical Research Center for Respiratory Disease, Xiangya Hospital, Central South University, Changsha, China; ${ }^{9}$ Department of Respiratory and Critical Care Medicine, Tongji Hospital, Tongji Medical College, Huazhong University of Science and Technology, Wuhan, China

Contributions: (I) Conception and design: All authors; (II) Administrative support: Y Gao, JP Zheng; (III) Provision of study materials or patients: XL Liang, J Du, L Chen, W Han, JM Liu, Y Lu, Y Peng, BR Zhao, T Wang; (IV) Collection and assembly of data: XL Liang, J Du, L Chen, W Han, JM Liu, Y Lu, Y Peng, BR Zhao, T Wang; (V) Data analysis and interpretation: XL Liang, WJ Guan, Y Gao, JP Zheng; (VI) Manuscript writing: All authors; (VII) Final approval of manuscript: All authors.

Correspondence to: Jin-Ping Zheng; Yi Gao. National Clinical Research Center for Respiratory Disease, State Key Laboratory of Respiratory Disease, Guangzhou Institute of Respiratory Health, First Affiliated Hospital of Guangzhou Medical University, No. 151 Yanjiang Road, Guangzhou 510120, China. Email: jpzhenggy@163.com; misstall2@163.com.

Background: Impulse oscillometry (IO) is a non-invasive pulmonary function test for measuring respiratory impedance. Available reference equations of IO indices for adults are limited. The aim of this study was to develop reference equations of IO indices for Chinese adults.

Methods: In a multicentral, cross-sessional study of IO in Chinese adults, IO data from healthy subjects were collected from 19 general hospitals across China between 2016 and 2018. Oscillometry measurements were conducted in accordance with recommendations of the European Respiratory Society (ERS). Multiple linear regression was performed to develop sex-specific reference equations of IO indices.

Results: IO measurements were performed in 1,318 subjects, of which 567 subjects were defined as healthy individuals with acceptable IO data and were included in the final analysis. Reference equations and limits of normal [lower limit of normal (LLN)/upper limit of normal (ULN)] of IO indices were developed separately for males and females. Height but not age was shown to be the most influential contributor to IO indices. The reference equations currently used in lung function laboratories predicted higher $R 5$ and $X 5$. Normal ranges of $R 5$ and $X 5$ recommended by the equipment manufacturer were clearly different from the ULN/ LLN derived from the reference equations.

Conclusions: Reference equations of IO indices for Chinese adults from a wide region were provided in this study. It is necessary to update new IO reference equations and adopt ULN/LLN as normal ranges of IO indices.

Trial Registration: This study was registered at www.clinicaltrials.gov as part of a larger study NCT03467880.

Keywords: Reference values; respiratory impedance; impulse oscillometry (IO); forced oscillation technique (FOT); adult 
Submitted Nov 24, 2020. Accepted for publication May 22, 2021.

doi: $10.21037 /$ jtd-20-3376

View this article at: https://dx.doi.org/10.21037/jtd-20-3376

\section{Introduction}

Impulse oscillometry (IO) is one of the techniques of respiratory oscillometry that measures respiratory impedance non-invasively (1). IO is regarded as a complementary tool to conventional lung function tests due to its minimal demand for cooperation and sensitivity in the evaluation of small airway function (2). Reports of IO as a useful tool in the assessment of asthma (3-6), chronic pulmonary obstructive diseases (7) and bronchiectasis (8) have increased its application in research and clinical settings.

In accordance with other lung function tests, choosing optimal reference values is crucial for the interpretation of IO. The first and also the most widely used reference equation of respiratory impedance with IO is the one proposed by Vogel et al. in 1994 (9). The sample population of Vogel's equations was from a German industrial city that suffered from air pollution and included smokers, which obviously did not meet the American Thoracic Society (ATS) recommended criteria for the data source of lung function reference values (10). Furthermore, the study only used age as predictor of the respiratory impedance, where later studies (11-17) have demonstrated that respiratory impedance is more associated with height and weight rather than age. This may have an impact on the predictive values and normal ranges of IO indices, thus decrease the capacity for IO to identify respiratory abnormality. Although some studies had focused on developing new reference equations of respiratory impedance by oscillometry, the available reference equations of IO indices for adults are limited (11-16,18-21). The lack of appropriate reference equations and normal ranges of IO have hindered the application of oscillometry in clinical practice.

The aim of the present study was to develop reference equations of IO indices that: (I) are based on data of healthy Chinese adults collected from a wide region and under standardized quality control; (II) provide normal limits of IO indices with up-to-date criteria for clinical use. We present the following article in accordance with the TRIPOD reporting checklist (available at https://dx.doi. org/10.21037/jtd-20-3376).

\section{Methods}

The study of IO in Chinese was a multicenter, crosssectional and observational study, and collected IO and spirometry reports from healthy subjects and patients with respiratory diseases in 20 general hospitals from 15 provincial regions throughout China between 2016 and 2018 (details of these hospitals are shown in Figure S1). IO data of healthy subjects were used to develop reference equations of IO in the present study. The study was conducted in accordance with the Declaration of Helsinki (as revised in 2013). The study was approved by ethics committee of the First Affiliated Hospital of Guangzhou Medical University (No. 2015-37) and informed consent was taken from all individual participants.

\section{Subject}

Subjects were recruited mainly from individuals who have regular check-ups in hospitals, volunteer students at colleges and the relatives of hospital patients. Selfreported questionnaire was used to collect medical history, history of smoking and occupational exposures, respiratory symptoms, and results of chest radiography within the last 6 months. Subjects who met the following criteria were included as healthy subjects: no history of smoking or smoked $<100$ cigarettes in their lifetime; no occupational exposures; no respiratory tract infections in the last 4 weeks; no chronic or recurrent respiratory symptoms including cough, expectoration, wheezing, or shortness of breath; reported no severe cardiopulmonary diseases or systematic diseases. Those who had abnormalities on chest radiography or spirometry were excluded.

\section{Oscillometry measurement}

A Masterscreen Impulse Oscillometry System (CareFusion, Hoechberg, Germany) was used for oscillometry measurements in this study. Oscillometry measurements were conducted following the official technical recommendations for oscillometry from the European Respiratory Society (ERS) (22). Verification of impedance was performed daily and a criterion of error $\leq 10 \%$ or $0.1 \mathrm{kPa} \cdot \mathrm{s} \cdot \mathrm{L}^{-1}$ was adopted. 
Measurements were performed in the sitting position with head in a neutral or slightly extended position, and the nose was closed by a nose clip. The cheeks were firmly supported by hands to reduce the effects of upper airway shunt. The subject was instructed to breath quietly at functional residual capacity level for 45-60 s. Measurements were repeated until three acceptable measurements were achieved, and the average of the three measurements was used for analysis. An acceptable measurement should have a data acquisition of at least $30 \mathrm{~s}$ and included five normal breaths without obvious artifacts like spikes in $Z$-time tracing or drifts in the volumetime tracing. The coherence of each measurement was $\geq 0.8$ at $5 \mathrm{~Hz}$ and $\geq 0.9$ at $20 \mathrm{~Hz}$. Unacceptable data were excluded from the analysis.

Based on the fundamentals of forced oscillation technique (FOT), oscillometry measures respiratory impedance $(Z)$ by superimposing pressure wave on the normal breathing (1). $Z$ includes resistance $(R)$ and reactance $(X) . R$ represents the resistive properties of respiratory system, and $X$ represents the capacitive and inert properties of respiratory system. IO indices analyzed in this study included $R$ and $X$ at different frequencies $(5-35 \mathrm{~Hz})$, the difference between and $R 5$ and $R 20$ ( $R 5-R 20)$, resonant frequency (fres), and low-frequency reactance area $(\mathrm{AX})$. The key indices for the normal limits analysis were $R 5$ and $X 5$, which are respectively recognized as total resistance and capacitance of respiratory system.

\section{Spirometry}

Spirometry (CareFusion, Hoechberg, Germany) was performed immediately after the oscillometry measurements as per the ATS/ERS guideline for spirometry (23). If spirometry was performed before the oscillometry, at least $3 \mathrm{~min}$ of rest was allowed for rest (22). Three acceptable measurements that met the quality control criteria of the ATS/ERS guidelines (24) were acquired and the best one was used in the analysis. Spirometric indices analyzed in this study were forced expiratory volume in the first second $\left(\mathrm{FEV}_{1}\right.$ ), forced vital capacity (FVC), $\mathrm{FEV}_{1} / \mathrm{FVC}$ and maximal mid-expiratory flow (MMEF). Reference values of spirometry were derived from the study of reference values for spirometry in Chinese aged 4-80 years (25).

\section{Statistical analysis}

As IO indices exhibited skewness distribution, the results were presented as median with interquartile range. MannWhitney $\mathrm{U}$ tests were performed for the comparisons of continuous indices. A P values $<0.05$ was considered statistically significant.

Reference equations were calculated separately for males and females using multivariate linear regression analysis. Scatter plots (see Figure S2) were drawn to observe the linear relationship between IO indices and predictor variables. Normal P-P plots and residual plots were drawn to examine the normality and equal variance of the residuals. As the residuals of fres and AX only displayed normality and equal variance after fres and $\mathrm{AX}$ were $\log$ transformed, thus fres and $\mathrm{AX}$ were calculated as $\log _{10}$ transformation (lgfres and $\lg \mathrm{AX}$ ) in the equations. Predictor variables (height, weight and age) were selected using the stepwise method, in which predictors would enter the model if $\mathrm{P}<0.05$ and were removed if $\mathrm{P}>0.10$. Fitness of the model was assessed by the coefficient of determination $\left(R^{2}\right)$. Normal limits of IO indices were calculated as followed: upper limit of normal (ULN) of $R=$ predictive value $+1.645 \times$ residual standard deviation (RSD), lower limit of normal (LLN) of $X=$ predictive value $-1.645 \times \mathrm{RSD}$.

For the development of prediction models with multivariate regression analysis, according to the rule of ten events per variable, assuming that the number of predictors of the equation is 3 , then the sample size would be at least 30 for male and female subjects. Subjects with missing data would be excluded from the analysis.

\section{Results}

In this study, a total number of 1,318 of subjects were recruited and finished the oscillometry measurements between 2016 and 2018 in 19 hospitals across China, 567 subjects from 13 hospitals were included in the final analysis (Figure 1 and Table S1). The baseline characteristics are presented in Table 1 and Figure 2. Height range was $154-186 \mathrm{~cm}$ in males and $142-176 \mathrm{~cm}$ in females. The spirometric indices $\mathrm{FEV}_{1}, \mathrm{FVC}, \mathrm{FEV}_{1} / \mathrm{FVC}$ and MMEF of the analyzed population were all within normal limits.

For the whole population, the median (interquartile range) of $R 5$ was $0.29(0.09) \mathrm{kPa} \cdot \mathrm{s} \cdot \mathrm{L}^{-1}, R 20$ was 0.27 $(0.08) \mathrm{kPa} \cdot \mathrm{s} \cdot \mathrm{L}^{-1}$, and $X 5$ was $-0.10(0.04) \mathrm{kPa} \cdot \mathrm{s} \cdot \mathrm{L}^{-1}$. Resistance at all frequencies in females were significantly higher than those in males, while reactance at all frequencies (except for $\mathrm{X} 15$ ) were more negative in females than in males (details are shown in Table S2).

Results of the reference equations for main IO indices are shown in Table 2 (complete results of other IO indices 


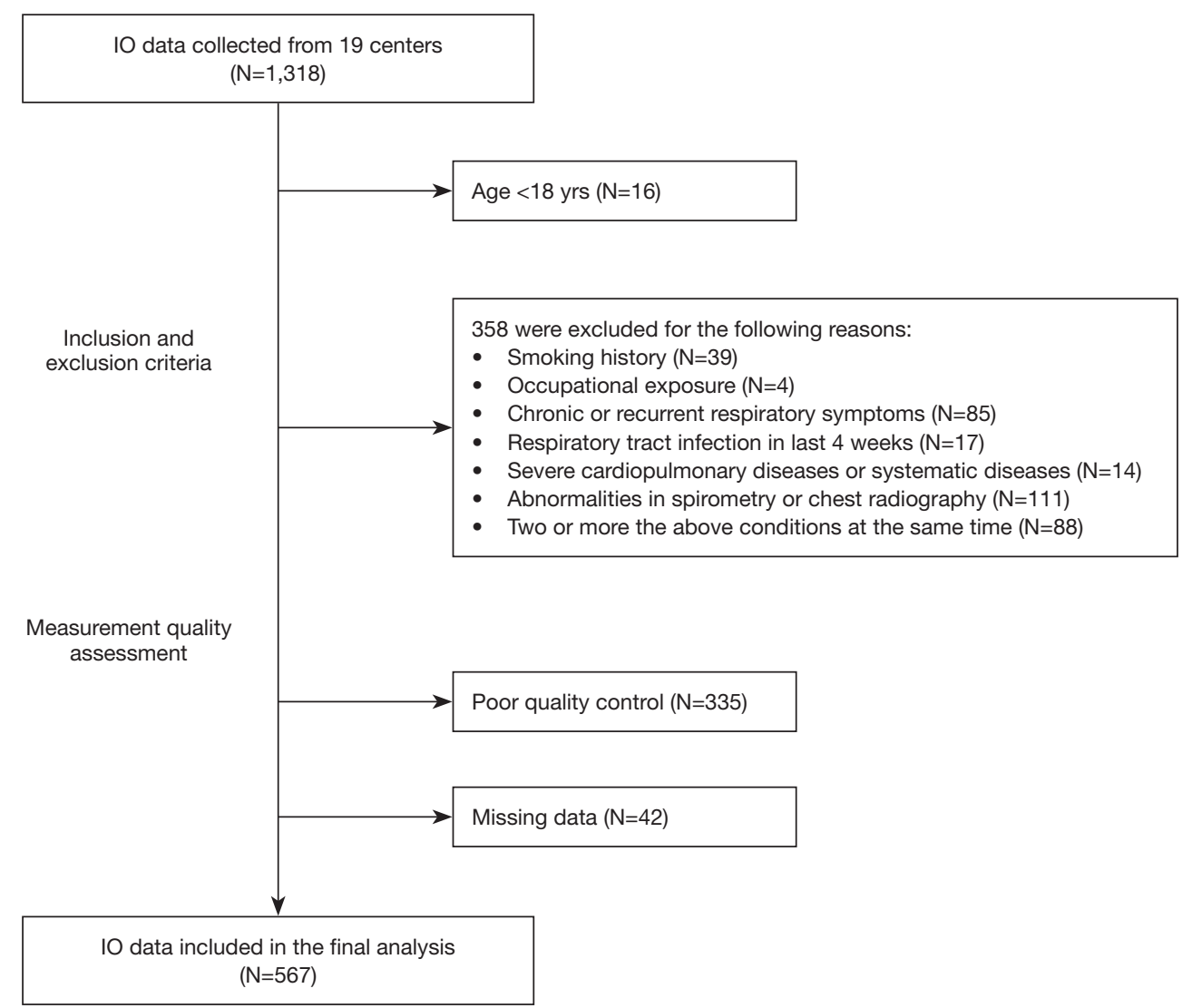

Figure 1 Flow chart of the inclusion and exclusion criteria for analyzed data. IO, impulse oscillometry.

Table 1 Baseline characteristics of the study population

\begin{tabular}{|c|c|c|c|}
\hline Baseline characteristics & Male $(\mathrm{N}=270)$ & Female (N=297) & $P$ value \\
\hline Height (cm) & $170.0(9.0)$ & $159.0(7.0)$ & $<0.001$ \\
\hline Weight (kg) & $69.0(15.1)$ & $56.0(12.0)$ & $<0.001$ \\
\hline BMI $\left(\mathrm{kg} / \mathrm{m}^{2}\right)$ & $23.7(4.4)$ & $21.9(4.4)$ & $<0.001$ \\
\hline FEV $_{1}$ z score & $0.28(1.24)$ & $0.16(1.16)$ & 0.213 \\
\hline FVC (L) & $4.66(0.99)$ & $3.34(0.62)$ & $<0.001$ \\
\hline FVC z score & $0.23(1.31)$ & $0.17(1.27)$ & 0.211 \\
\hline $\mathrm{FEV}_{1} / \mathrm{FVC}$ & $0.83(0.07)$ & $0.84(0.07)$ & 0.002 \\
\hline MMEF z score & $0.12(1.23)$ & $0.05(1.26)$ & 0.461 \\
\hline
\end{tabular}

Data are presented as median (interquartile range). BMI, body mass index; $\mathrm{FEV}_{1}$, forced expiratory volume in the first second; FVC, forced vital capacity; MMEF, maximum mid-expiratory flow. 

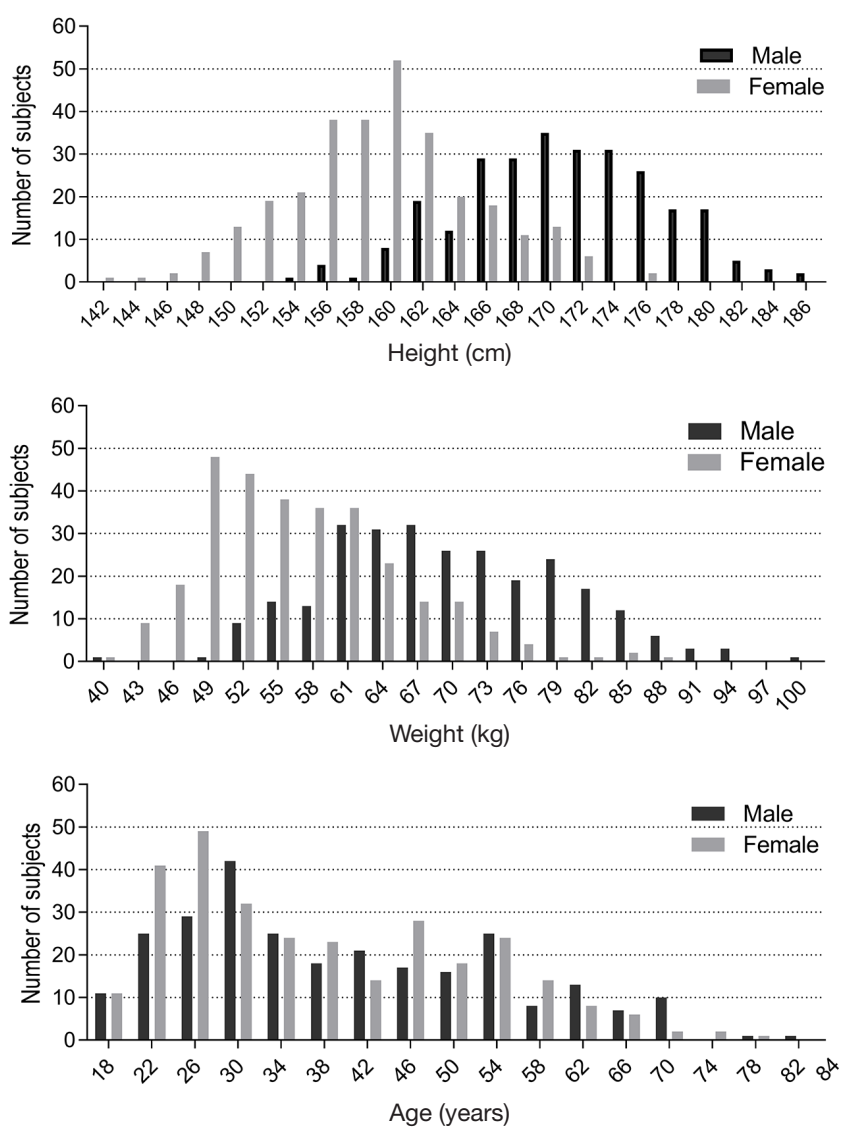

Figure 2 Distribution of height, weight and age of the study population by gender.

are shown in Tables $\mathrm{S} 3, \mathrm{~S} 4)$. Except for $R 35$ in males, all IO indices in this study derived significant reference equations with height and/or weight as predictors. $R^{2}$ of the equations ranged from 0.0154 to 0.250 and tended to be smaller in equations of the impedance at higher frequencies.

In the equations of most IO indices, height was shown to be the most influential predictor as it contributed the largest $R^{2}$ changes in the prediction models. Height was negatively associated with $R$, fres and AX, and positively associated with $X$. On the contrary, weight showed a positive association with $R$, fres and $\mathrm{AX}$, and negative association with $X$. Age was shown to be predictor to some indices including $X 5, X 25$, and $X 35$ in both genders and $Z 5, R 5$, and $\lg \mathrm{AX}$ in females (Tables $\mathrm{S} 3, \mathrm{~S} 4$ ). However, the scatter plots (Figure S2) between these indices and age did not display notable linear relationships.

For further comparisons of reference values of previous studies [Vogel et al. (9), Newbury et al. (15), and Schulz et al. (18)] and the present one, reference values of $R 5$ and $X 5$ were compared as a function of height, with age fixed at 50 years, and weight was calculated by a fixed body mass index (BMI) of $23 \mathrm{~kg} / \mathrm{m}^{2}$ (the median of our study subjects). Results are in Figure 3. Also, differences between the actual values and the reference values by different equations in healthy subjects were compared in Figures S3-S5.

\section{Discussion}

Sex-specific reference equations for respiratory impedance were developed based on large-scale data of healthy Chinese adults from a wide region in a multicenter IO study.

\section{Contributors to the respiratory impedance}

As pulmonary function is associated with physiological changes during growth and aging, reference equations of 
Table 2 Reference equations of the main IO indices

\begin{tabular}{|c|c|c|c|}
\hline 10 indices & Equations & RSD & $R^{2}$ \\
\hline$Z 5$ & $F: 0.9110-0.0042 \times H+0.0023 \times W-0.0008 \times A$ & 0.0493 & 0.1673 \\
\hline \multirow[t]{2}{*}{$R 5$} & M: $0.6275-0.0030 \times \mathrm{H}+0.0019 \times \mathrm{W}$ & 0.042 & 0.1789 \\
\hline & $F: 0.8103-0.0038 \times H+0.0024 \times W-0.0005 \times A$ & 0.0491 & 0.1606 \\
\hline$R 20$ & $\mathrm{~F}: 0.5042-0.0013 \times \mathrm{H}$ & 0.0442 & 0.0282 \\
\hline \multirow[t]{2}{*}{$R 5-R 20$} & M: $0.2485-0.0018 \times \mathrm{H}+0.0010 \times W$ & 0.0205 & 0.2249 \\
\hline & $F: 0.2360-0.0019 \times \mathrm{H}+0.0017 \times \mathrm{W}$ & 0.0306 & 0.1865 \\
\hline$x 5$ & $\mathrm{M}:-0.3100+0.0013 \times \mathrm{H}+0.0002 \times \mathrm{A}$ & 0.0195 & 0.1105 \\
\hline Igfres & $F: 1.8261-0.0067 \times H+0.0051 \times W$ & 0.0805 & 0.2505 \\
\hline \multirow[t]{2}{*}{$\lg A X$} & $\mathrm{M}: 1.3268-0.0142 \times \mathrm{H}+0.0043 \times \mathrm{W}$ & 0.2124 & 0.1179 \\
\hline & $F: 1.6639-0.0166 \times H+0.0089 \times W-0.0029 \times A$ & 0.2037 & 0.1540 \\
\hline
\end{tabular}

$\mathrm{IO}$, impulse oscillometry; RSD, residual standard deviation; $R^{2}$, coefficient of determination; $Z 5$, total respiratory impedance at $5 \mathrm{~Hz}$; $R 5$, resistance at $5 \mathrm{~Hz}$; $R 20$, resistance at $20 \mathrm{~Hz}$; $R 5-R 20, R 5$ minus $R 20$; X5, reactance at $5 \mathrm{~Hz}$; fres, resonant frequency; $A X$, low-frequency reactance area; $M$, male; $F$, female; $H$, height; $W$, weight; $A$, age.
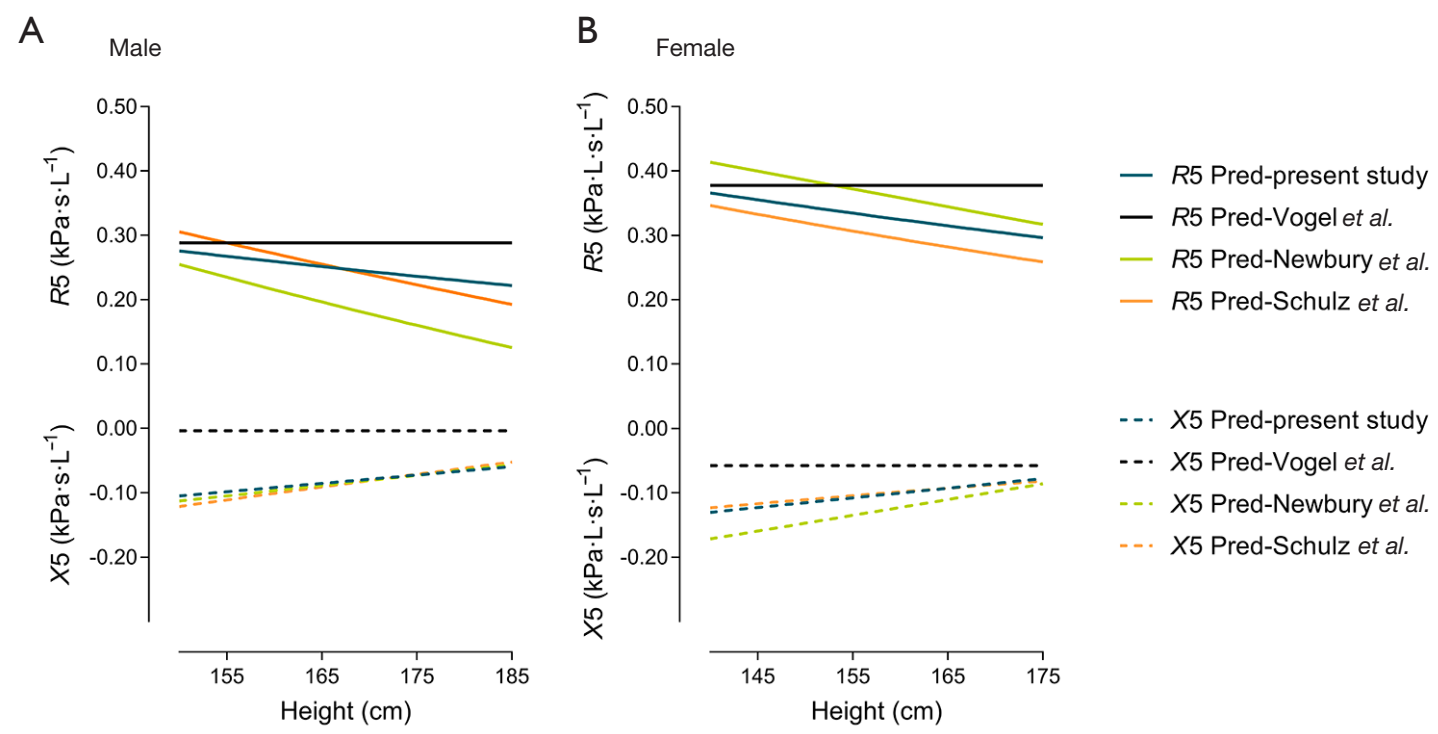

Figure 3 Comparison of the Pred of $R 5$ and $X 5$ predicted by different equations. Results are shown as a function of height, with age fixed at 50 years, and weight was calculated by a fixed BMI of $23 \mathrm{~kg} / \mathrm{m}^{2}$ (the median of our study population). Solid lines indicate Pred of $R 5$, and dashed lines indicate Pred of X5. Pred, predictive values; BMI, body mass index. 
pulmonary function commonly include anthropometric variables such as sex, age, height and weight, in order to justify the contributory effects of these factors to lung function. Our study found that height was the most influential contributor to respiratory impedance measured with IO, with that taller individuals had higher $R$ and less negative $X$. This finding is consistent with the previous studies (11-17,19,21,26). As shown in Table 3, though the coefficients or forms of the predictors in the IO equations are different, the tendency of the effect of predictors in most equations remains the same; that is, height is negatively correlated with $R 5$ and $R 20$, and positively correlated with $X 5$. The association between height and respiratory resistance can be explained by the effect that height contributes to the diameter of the airways and lung volume. This could also explain the discrepancies of respiratory impedance between males and females. In contrast, weight displayed a positive association with $R$. The decreased lung volume and ventilation heterogeneity reported in the obese subjects $(27,28)$ may account for the higher respiratory resistance in the obese. However, the mechanism behind how body weight affects respiratory impedance in subjects with normal weight is still not clear since most studies have focused on overweight or obese individuals. Although age did not appear to be a marked contributor to $R$ in adults in our study, a negative dependence on age for $R$ has been reported in studies of children and adolescences $(29,30)$. Thus, the effect of age on $R$ may be related to the rapid physiological changes during growth, especially on the growth of the respiratory system in children and adolescences.

\section{Reference equations of respiratory impedance with IO}

Since age is shown to have little impact on respiratory impedance in adults, it is no surprise that in Figure 3, marked differences of predictive values were found between the Vogel's equations and the equations from other three representative studies [Newbury et al. (15), Schulz et al. (18) and the present study], as age is the only predictor in Vogel's equations (9). Given that many lung function laboratories are still using Vogel's equations, it is important for the physicians to note that Vogel's equations predict higher $R 5$ and $X 5$ than other equations, especially for $X 5$, and the differences are greater in tall subjects for $R 5$ and in short subjects for $X 5$. Undoubtedly, developing a more appropriate equation is imperative.
As summarized in Table 3, since Vogel's equations were developed, 10 studies have developed new equations of IO indices in adults, and 7 of these were from China. However, most of these studies have limitations such as lack of quality control of IO data or small sample sizes [Fang et al. (12), Shiota et al. (13), Newbury et al. (15), Ni et al. (14), Wang et al. (16)]. Among these studies, only 6 studies had mentioned the number of IO measurements for each subject, only 4 studies [Wang et al. (16), Schulz et al. (18), Zhang et al. (19), Shu et al. (20)] had mentioned the requirements of repeatability, and 3 studies [Shiota et al. (13), Newbury et al. (15), Schulz et al. (18)] had mentioned the acceptable criteria for the IO measurements. As the variations of oscillometry are greater than spirometry (31), multiple measurements and strict quality control are particularly important in oscillometry measurements to ensure the repeatability and reliability of the data. Regarding sample size, studies from Shiota et al. (13) and Newbury et al. (15) were based on small sample sizes, with 166 and 125 subjects, respectively. This may decrease the reliability and applicability of their equations as a study have shown that at least 150 males and 150 females are required to validate reference equations of lung function tests in individual laboratories (32). Also, Shiota's equation did not take sex into account, whereas sex-related differences in IO indices have been reported in the present and former studies (21). Schulz's study (18) was based on data from a relatively large sample size and with clear quality control criteria. Similar values of $R 5$ and $X 5$ produced by Schulz's study and the present study in Figure 3 provide evidence of the reliability of our reference equations.

Although 7 studies from China have developed reference equations of IO indices $(11,12,14,16,19,20,26)$ (Table 3), all of these studies were based on local sample populations, which may be less representative of the whole population of China, as China is a country with large territory and population. Heterogeneity in the inclusion criteria of participants and quality control also hinder the integration of these databases. Our study was a multicenter study that included data from a wide region across China, with uniform inclusion criteria and standardized quality control. Therefore, this study is more representative of the general population and produces more reliable data.

\section{Normal ranges of $\mathrm{IO}$ indices}

Despites the fact that ERS had published official recommendations for the application of oscillometry in the clinical practice $(22,33)$, there are no acknowledged 


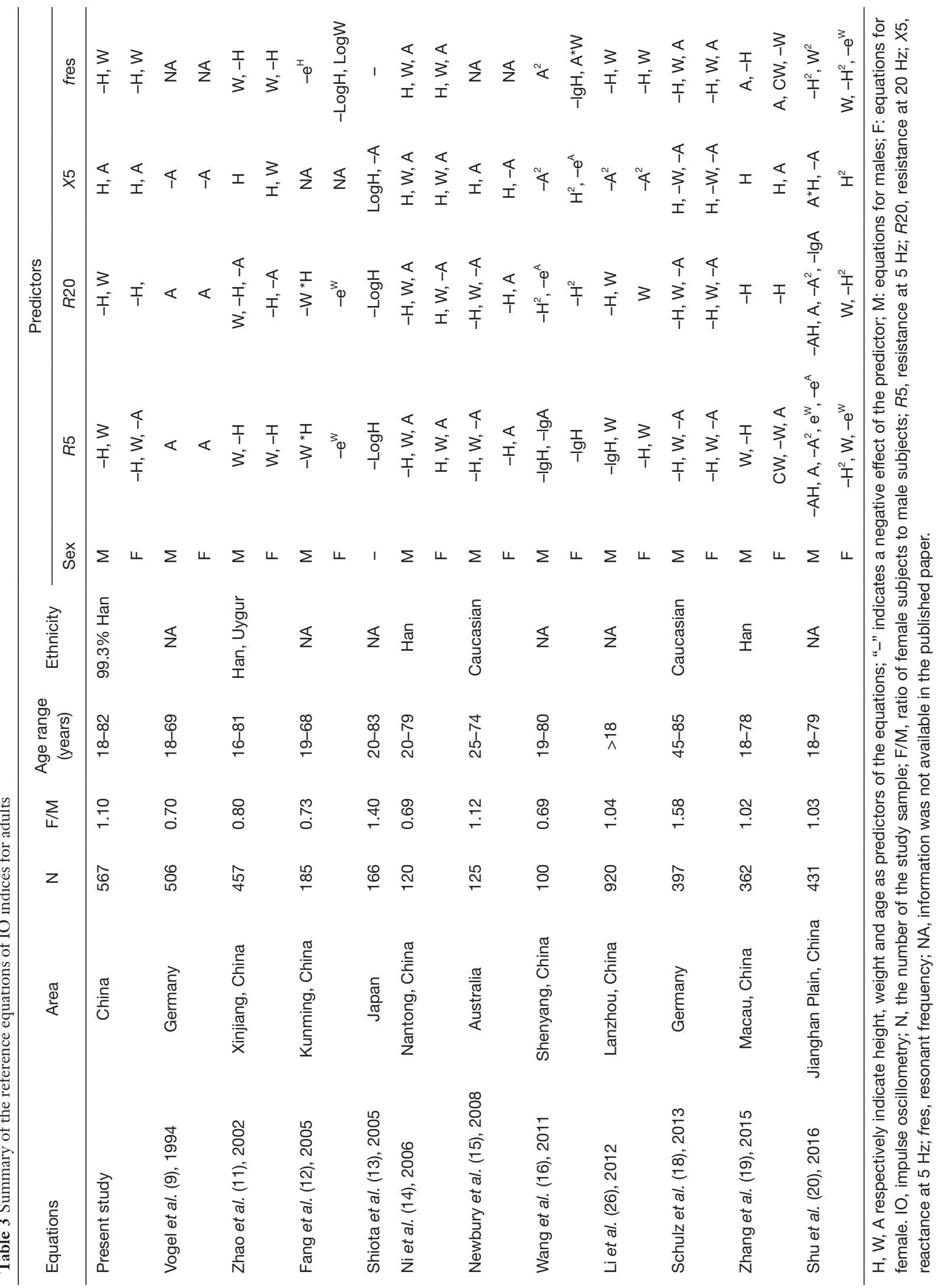



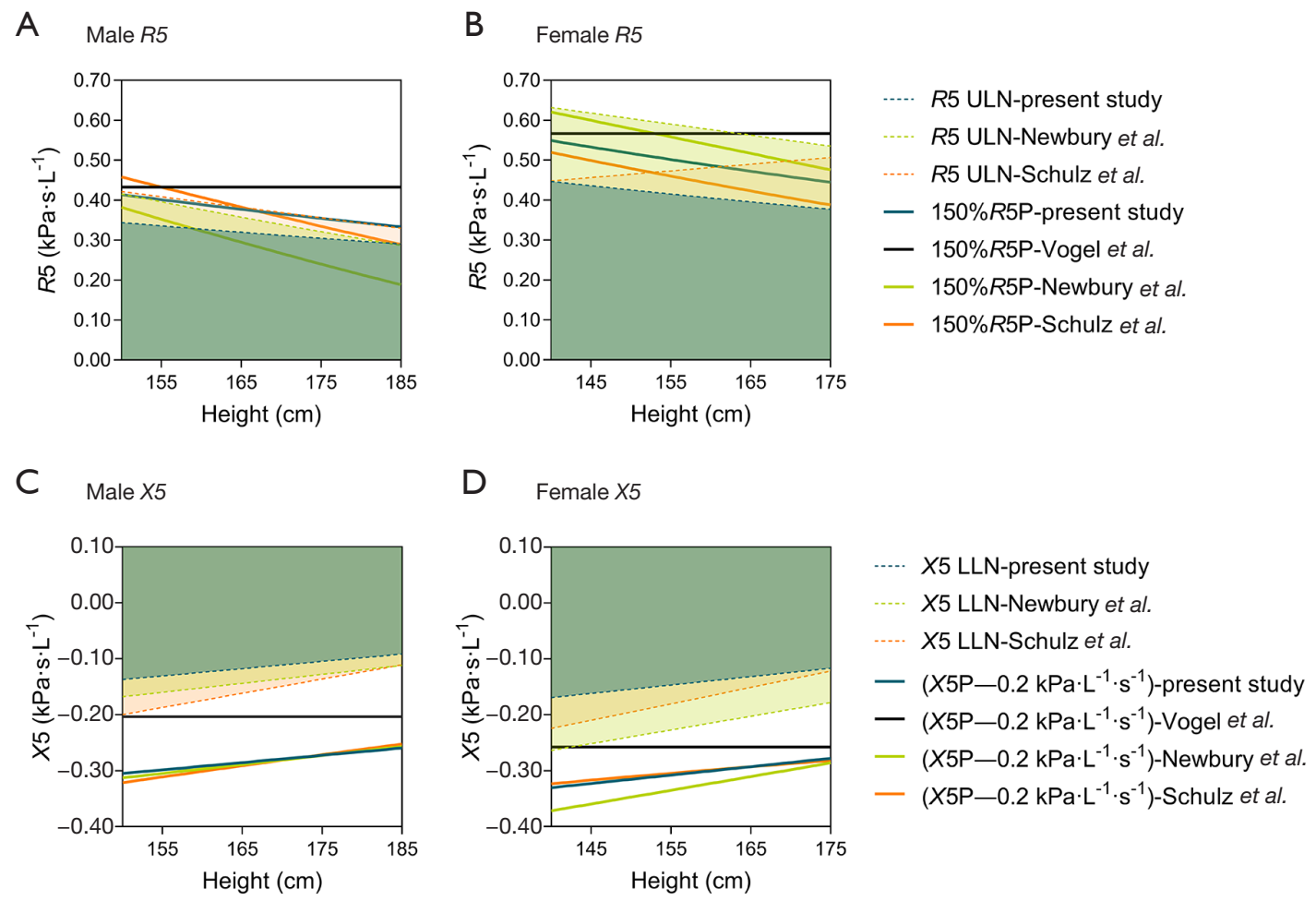

Figure 4 Comparisons of the normal ranges of $R 5$ and $X 5$ derived by different equations. Colored area under the dotted lines indicates ULN of $R 5$ or LLN of $X 5$. Solid lines indicate $150 \% R 5 \mathrm{P}$ or the predictive values of $X 5$ minus $0.2 \mathrm{kPa} \cdot \mathrm{s} \cdot \mathrm{L}^{-1}\left(X 5 \mathrm{P}-0.2 \mathrm{kPa} \cdot \mathrm{s} \cdot \mathrm{L}^{-1}\right)$. As the RSD of Vogel's equations is not available, the ULN/LLN with Vogel's equations is not shown. ULN, upper limit of normal; LLN, lower limit of normal; $150 \%$ R5P, $150 \%$ of the predictive values of $R 5$; RSD, residual standard deviation.

criteria for the normal ranges of respiratory impedance with oscillometry, probably due to the lack of systematic studies concerning on normative values of respiratory impedance. The IO equipment manufacturer recommends using $150 \%$ of the predicted value as the normal limit for $R 5$ and $R 20$, and predicted value minus $0.2 \mathrm{kPa} \cdot \mathrm{s} \cdot \mathrm{L}^{-1}$ as the normal limit of $X 5$. The former was derived from the report of a bronchial challenge test study showing that a $20 \%$ decrease in $\mathrm{FEV}_{1}$ was comparable to a $50 \%$ increase in airway resistance (1). However, ATS guidelines for pulmonary function tests reported in 2017 have recommended using LLN/ULN as the criteria of abnormal of pulmonary function (10). As is shown in Figure 4, predicted $X 5$ minus $0.2 \mathrm{kPa} \cdot \mathrm{s} \cdot \mathrm{L}^{-1}\left(X 5 \mathrm{P}-0.2 \mathrm{kPa} \cdot \mathrm{s} \cdot \mathrm{L}^{-1}\right)$ was significantly more negative than the LLN of $X 5$, regardless of the equation used. The $150 \%$ of predicted $R 5(150 \% R 5 \mathrm{P})$ was much higher than the ULN of $R 5$ produced by our equations, and marked differences were also shown in the comparison of ULN of $R 5$ and $150 \%$ R5P produced by Newbury' equations in males and Schulz's equations in females. The above differences between the ULN/LLN and the normal limits currently used in laboratories will apparently increase the risk of misdiagnosis. Under the increasing application of oscillometry in clinical practice, it is necessary to update new equations and normal ranges of oscillometry. The validation of our new equations and normal ranges of IO in patients with respiratory diseases will be further analyzed and discussed in our later reports.

\section{Limitations}

There were limitations to the present study. First, due to the practical limitations, our study population was not a random sample and may be less representative of the whole healthy population. Nevertheless, multicenter sources of data and strict inclusive criteria for healthy subjects in this study provide a guarantee of the representativeness of a healthy population. To date, our equations are the most representative and reliable for healthy Chinese adults. Second, our equations are based on the data of Chinese 
population, its use in other populations or ethnicities may be limited. However, we believe that these data may be a foundation or promotion to the development of multiethnic reference equations of oscillometry in the future, and our findings about the inappropriateness of the current normal ranges of IO indices may provide evidences for the update of the internationally technical standards. Third, as the IO data from children and adolescents in multicenter study of IO in Chinese were not enough to develop reference equations, we failed to develop continuous reference equations with a full age range. Studies containing a larger number of healthy children and adolescents with a randomized sample are needed in the future.

\section{Conclusions}

In summary, based on the data of a large-scale healthy population in the multicenter IO study in China, we developed new reliable reference equations of respiratory impedance with IO. Also, we found that the normal ranges of IO indices wildly used in laboratories were clearly different from the ULN/LLN derived from the reference equations. It is necessary to update new IO reference equations and adopt ULN/LLN as normal ranges of IO indices for better use of osicllometry in clinical practice.

\section{Acknowledgments}

The authors wish to thank to the following people and centers for offering data to this manuscript: Tie-Ying Sun and Yi-Meng Yang (Beijing Hospital); Li Xiang (Beijing Children's Hospital, Capital Medical University); Cheng Zhang (Guizhou Provincial People's Hospital); Gui-Hua Zhao (Henan Provincial People's Hospital); Ming-Juan Zhou (Guangdong Provincial Hospital of Traditional Chinese Medicine); Chun-Yan Zheng and De-Xiang Wang (Qilu Hospital of Shandong University); Ning Zhou (Tianjin Medical University General Hospital); Xu-Hua Zhang (General Hospital of Ningxia Medical University); Xiao-Ju Liu and Hai-Rong Bao (The First Hospital of Lanzhou University); Xin Chen (Zhujiang Hospital of Southern Medical University).

Funding: This work was supported by the National Key Research and Develop Program of China (No. 2018YFC1311900); Science and Technology Planning Project of Guangdong Province (No. 2014A020212358); and the National Science and Technology Support Plan (No.
2015BAI12B10).

\section{Footnote}

Reporting Checklist: The authors have completed the TRIPOD reporting checklist. Available at https://dx.doi. org/10.21037/jtd-20-3376

Conflicts of Interest: All authors have completed the ICMJE uniform disclosure form (available at https://dx.doi. org/10.21037/jtd-20-3376). The authors have no conflicts of interest to declare.

Ethical Statement: The authors are accountable for all aspects of the work in ensuring that questions related to the accuracy or integrity of any part of the work are appropriately investigated and resolved. The study was conducted in accordance with the Declaration of Helsinki (as revised in 2013). The study was approved by ethics committee of the First Affiliated Hospital of Guangzhou Medical University (No. 2015-37) and informed consent was taken from all individual participants.

Open Access Statement: This is an Open Access article distributed in accordance with the Creative Commons Attribution-NonCommercial-NoDerivs 4.0 International License (CC BY-NC-ND 4.0), which permits the noncommercial replication and distribution of the article with the strict proviso that no changes or edits are made and the original work is properly cited (including links to both the formal publication through the relevant DOI and the license). See: https://creativecommons.org/ licenses/by-nc-nd/4.0/.

\section{References}

1. Smith HJ, Reinhold P, Goldman MD. Forced oscillation technique and impulse oscillometry. Eur Respir Mon 2005;31:72-105.

2. Galant SP, Komarow HD, Shin HW, et al. The case for impulse oscillometry in the management of asthma in children and adults. Ann Allergy Asthma Immunol 2017;118:664-71.

3. Shi Y, Aledia AS, Tatavoosian AV, et al. Relating small airways to asthma control by using impulse oscillometry in children. J Allergy Clin Immunol 2012;129:671-8.

4. Shi Y, Aledia AS, Galant SP, et al. Peripheral airway impairment measured by oscillometry predicts loss of 
asthma control in children. J Allergy Clin Immunol 2013;131:718-23.

5. Shin YH, Yoon JW, Choi SH, et al. Use of impulse oscillometry system in assessment of asthma severity for preschool children. J Asthma 2013;50:198-203.

6. Schulze J, Biedebach S, Christmann M, et al. Impulse Oscillometry as a Predictor of Asthma Exacerbations in Young Children. Respiration 2016;91:107-14.

7. Liu Z, Lin L, Liu X. Clinical application value of impulse oscillometry in geriatric patients with COPD. Int J Chron Obstruct Pulmon Dis 2017;12:897-905.

8. Guan WJ, Gao YH, Xu G, et al. Impulse oscillometry in adults with bronchiectasis. Ann Am Thorac Soc 2015;12:657-65.

9. Vogel J, Smidt U. Impulse oscillometry: analysis of lung mechanics in general practice and the clinic, epidemiological and experimental research. Frankfurt: pmi-Verlag-Gruppe, 1994.

10. Culver BH, Graham BL, Coates AL, et al. American Thoracic Society Documents Recommendations for a Standardized Pulmonary Function Report An Official American Thoracic Society Technical Statement. Am J Respir Crit Care Med 2017;196:1463-72.

11. Zhao M, Han A, Fang J. Determination of respiratory impedance of healthy adults by pulsating pulmonary function. Chin J Tuberc Respir Dis 2002;25:636.

12. Fang M, Chen Y, Liu A, et al. Measurement of respiratory impedance by means of impulse oscillometry in healthy adults in the Kunming area. Clin Pulmonol 2005;9:565-7.

13. Shiota S, Katoh M, Fujii M, et al. Predictive equations and the reliability of the impulse oscillatory system in Japanese adult subjects. Respirology 2005;10:310-5.

14. Ni S, Lv X, Feng J, et al. Respiratory impedance measured with impulse oscillometry in healthy adults in Nantong area. Chinese Medical Journal of Communications 2006;20:58-59, 61.

15. Newbury W, Crockett A, Newbury J. A pilot study to evaluate Australian predictive equations for the impulse oscillometry system. Respirology 2008;13:1070-5.

16. Wang T, Tan M, Zheng H. Analysis of the Normal Values of Pulmonary Function by Impulse Oscillometry in Healthy Adults in Shenyang. Journal of China Medical University 2011;40:340-2.

17. Oostveen E, Boda K, van der Grinten CP, et al. Respiratory impedance in healthy subjects: baseline values and bronchodilator response. Eur Respir J $2013 ; 42: 1513-23$.
18. Schulz H, Flexeder C, Behr J, et al. Reference values of impulse oscillometric lung function indices in adults of advanced age. PLoS One 2013;8:e63366.

19. Zhang X, Zheng J, Chen Y, et al. Investigations of impulse oscillation technique and predictive equations in Macao healthy adults. Chinese Journal of Practical Internal Medicine 2015;35:431-5.

20. Shu Y, Li J. Analysis of normal values of pulmonary function with impulsive oscillation in healthy adults in jianghan plain. Med Inf 2016;29:108-9.

21. Kalchiem-Dekel O, Hines SE. Forty years of reference values for respiratory system impedance in adults: 19772017. Respir Med 2018;136:37-47.

22. Oostveen E, MacLeod D, Lorino H, et al. The forced oscillation technique in clinical practice: methodology, recommendations and future developments. Eur Respir J 2003;22:1026-41.

23. Miller MR, Hankinson J, Brusasco V, et al. Standardisation of spirometry. Eur Respir J 2005;26:319-38.

24. Graham BL, Steenbruggen I, Miller MR, et al. Standardization of Spirometry 2019 Update. An Official American Thoracic Society and European Respiratory Society Technical Statement. Am J Respir Crit Care Med 2019;200:e70-88.

25. Jian W, Gao Y, Hao C, et al. Reference values for spirometry in Chinese aged $4-80$ years. J Thorac Dis 2017;9:4538-49.

26. Li F, Wang X, Wan Y, et al. Analysis of the normal Values of pulmonary function by impulse oscillometry in healthy adults in Lanzhou. Prog Microbiol Immunol 2012;40:34-7.

27. Salome CM, King GG, Berend N. Physiology of obesity and effects on lung function. J Appl Physiol (1985) 2010;108:206-11.

28. Pellegrino R, Gobbi A, Antonelli A, et al. Ventilation heterogeneity in obesity. J Appl Physiol (1985) 2014;116:1175-81.

29. Amra B, Soltaninejad F, Golshan M. Respiratory resistance by impulse oscillometry in healthy Iranian children aged 5-19 years. Iran J Allergy Asthma Immunol 2008;7:25-9.

30. Gochicoa-Rangel L, Torre-Bouscoulet L, MartínezBriseño D, et al. Values of impulse oscillometry in healthy mexican children and adolescents. Respir Care 2015;60:119-27.

31. Timonen KL, Randell JT, Salonen RO, et al. Shortterm variations in oscillatory and spirometric lung function indices among school children. Eur Respir J 


$$
\text { 1997;10:82-7. }
$$

32. Quanjer PH, Stocks J, Cole TJ, et al. Influence of secular trends and sample size on reference equations for lung function tests. Eur Respir J 2011;37:658-64.

Cite this article as: Liang $\mathrm{XL}$, Gao Y, Guan WJ, Du J, Chen L, Han W, Liu JM, Lu Y, Peng Y, Zhao BR, Wang T, Zheng JP. Reference values of respiratory impedance with impulse oscillometry in healthy Chinese adults. J Thorac Dis 2021;13(6):3680-3691. doi: 10.21037/jtd-20-3376
33. King GG, Bates J, Berger KI, et al. Technical standards for respiratory oscillometry. Eur Respir J 2020;55:1900753. 


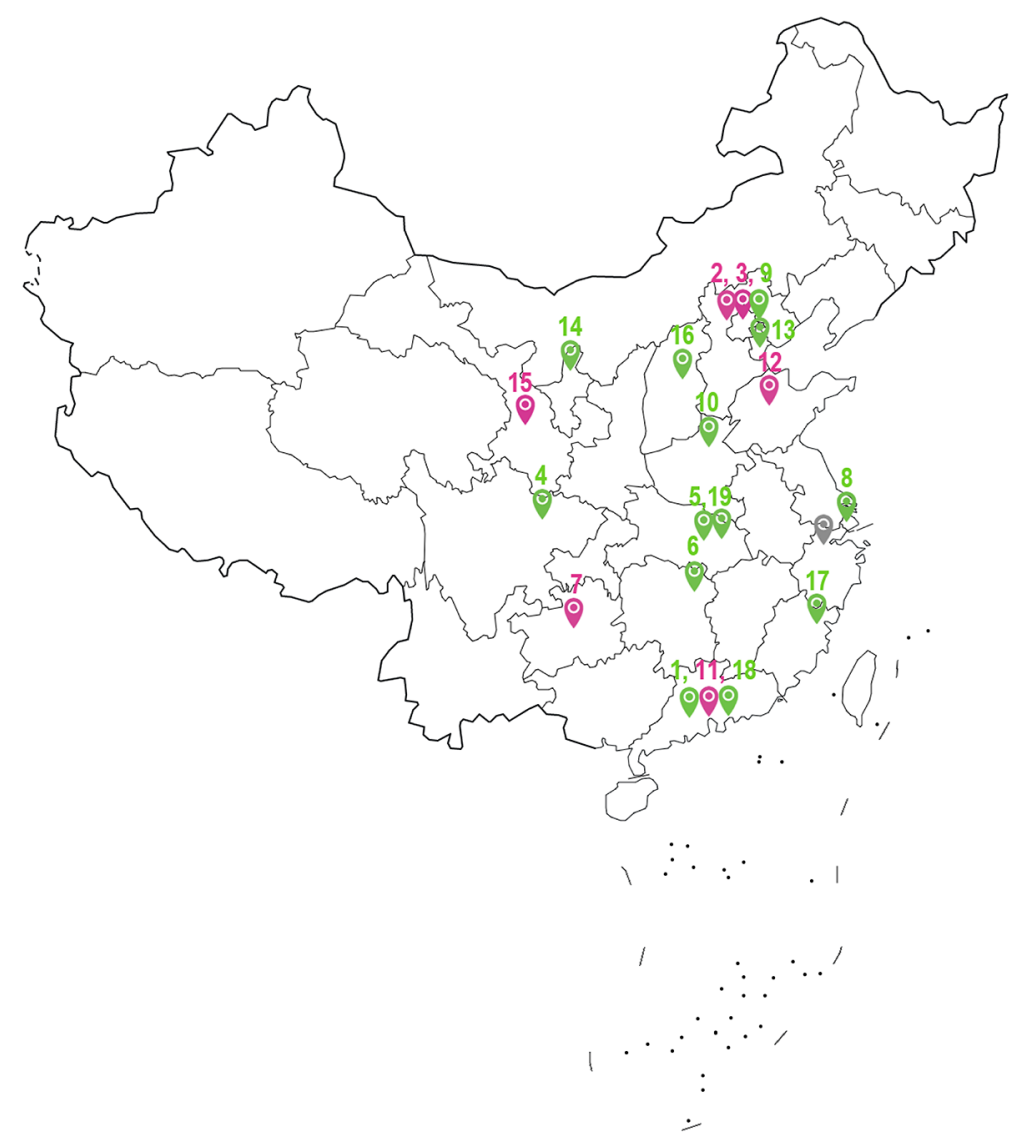

Figure S1 Locations of the 20 centers in multicenter study of IO in China. The multicenter study of IO in China have 20 participated centers, which are tertiary hospitals that have started performing IO in the lung function laboratories for clinical use. Green marks indicate centers that provided IO data included in the final analysis of reference equations, pink marks indicate centers that collected IO data of healthy subjects but not being included in the final analysis. Grey mark indicates center that provided no IO data of healthy subjects but data of respiratory diseases in the study. IO, impulse oscillometry. 

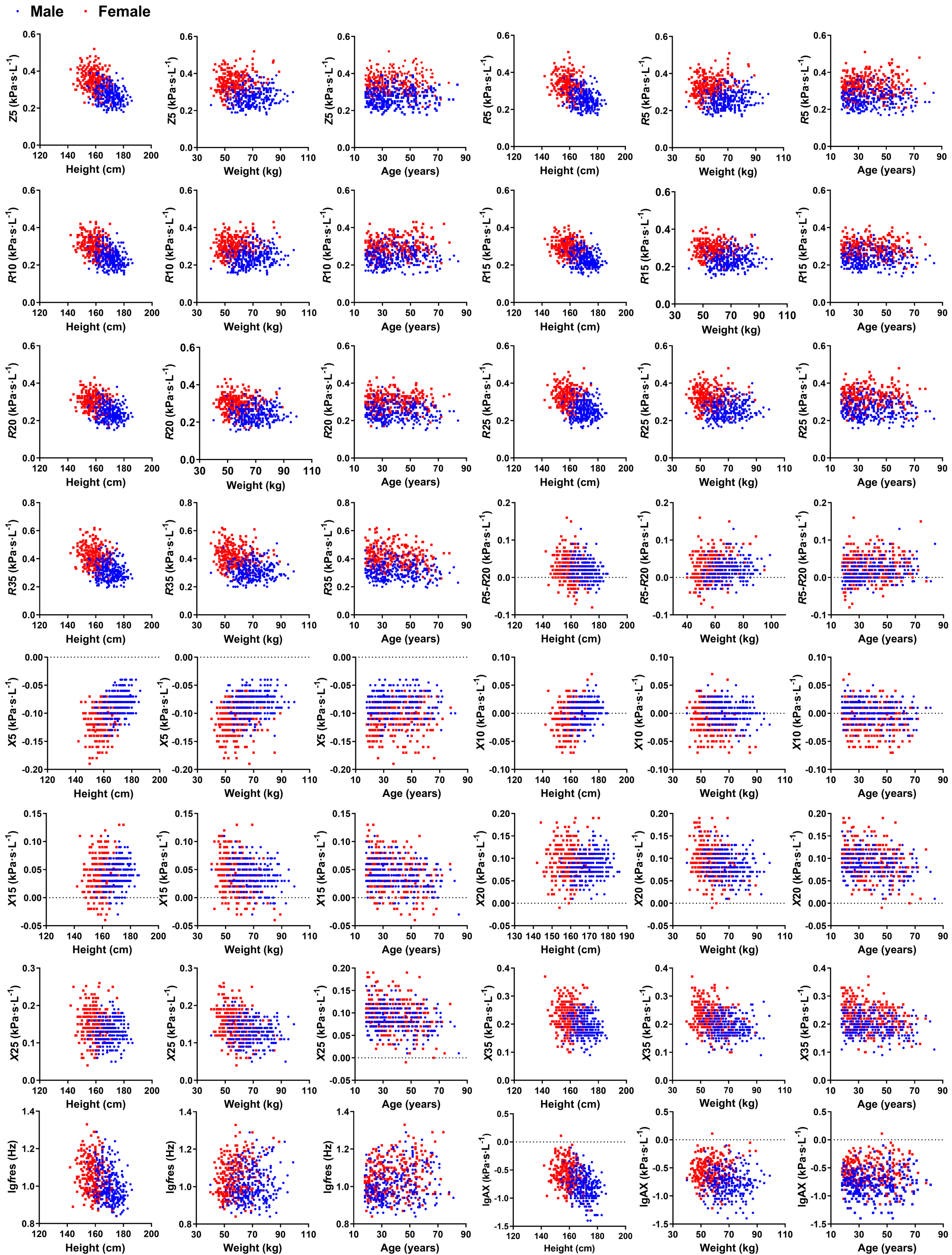

Figure S2 Scatter plots between IO indices and height, weight, age of the study population. IO, impulse oscillometry. 
Table S1 Numbers of collected data and analyzed data of each centers

\begin{tabular}{|c|c|c|}
\hline Centers & $\begin{array}{c}\text { Number of } \\
\text { collected data }\end{array}$ & $\begin{array}{c}\text { Number of } \\
\text { analyzed data }\end{array}$ \\
\hline The First Affiliated Hospital of Guangzhou Medical University & 73 & 45 \\
\hline Beijing Hospital & 187 & 0 \\
\hline Beijing Children's Hospital, Capital Medical University & 5 & 0 \\
\hline West China Hospital of Sichuan University & 144 & 129 \\
\hline Tongji Hospital Affiliated to Tongji Medical College of Huazhong University of Science and Technology & 71 & 11 \\
\hline Xiangya Hospital, Central South University & 52 & 26 \\
\hline Guizhou Provincial People's Hospital & 28 & 0 \\
\hline Shanghai Pulmonary Hospital & 108 & 78 \\
\hline Beijing Chao-Yang Hospital, Capital Medical University & 55 & 44 \\
\hline Henan Provincial People's Hospital & 30 & 1 \\
\hline Guangdong Provincial Hospital of Traditional Chinese Medicine & 140 & 0 \\
\hline Qilu Hospital of Shandong University & 33 & 0 \\
\hline Tianjin Medical University General Hospital & 30 & 1 \\
\hline General Hospital of Ningxia Medical University & 3 & 2 \\
\hline The First Hospital of Lanzhou University & 1 & 0 \\
\hline Shanxi Bethune Hospital & 124 & 92 \\
\hline The First Affiliated Hospital of Fujian Medical University & 185 & 100 \\
\hline Zhujiang Hospital of Southern Medical University & 3 & 2 \\
\hline Union Hospital of Tongji Medical College, Huazhong University of Science and Technology & 51 & 36 \\
\hline Total & 1,318 & 567 \\
\hline
\end{tabular}

Table S2 Median (interquartile range) of IO indices in the study population and comparisons between genders

\begin{tabular}{|c|c|c|c|c|}
\hline IO indices & Total $(n=567)$ & Male $(n=270)$ & Female $(n=297)$ & $P$ value \\
\hline$Z 5\left(\mathrm{kPa} \cdot \mathrm{L}^{-1} \cdot \mathrm{s}^{-1}\right)$ & $0.31(0.10)$ & $0.27(0.06)$ & $0.35(0.07)$ & $<0.001$ \\
\hline$R 5\left(\mathrm{kPa} \cdot \mathrm{L}^{-1} \cdot \mathrm{s}^{-1}\right)$ & $0.29(0.09)$ & $0.26(0.07)$ & $0.32(0.07)$ & $<0.001$ \\
\hline$R 10\left(\mathrm{kPa} \cdot \mathrm{L}^{-1} \cdot \mathrm{s}^{-1}\right)$ & $0.27(0.08)$ & $0.23(0.07)$ & $0.29(0.06)$ & $<0.001$ \\
\hline$R 15\left(\mathrm{kPa} \cdot \mathrm{L}^{-1} \cdot \mathrm{s}^{-1}\right)$ & $0.26(0.08)$ & $0.23(0.06)$ & $0.29(0.06)$ & $<0.001$ \\
\hline$R 20\left(\mathrm{kPa} \cdot \mathrm{L}^{-1} \cdot \mathrm{s}^{-1}\right)$ & $0.27(0.08)$ & $0.24(0.06)$ & $0.30(0.06)$ & $<0.001$ \\
\hline$R 25\left(\mathrm{kPa} \cdot \mathrm{L}^{-1} \cdot \mathrm{S}^{-1}\right)$ & $0.29(0.10)$ & $0.25(0.07)$ & $0.32(0.07)$ & $<0.001$ \\
\hline$R 35\left(\mathrm{kPa} \cdot \mathrm{L}^{-1} \cdot \mathrm{s}^{-1}\right)$ & $0.31(0.08)$ & $0.31(0.08)$ & $0.40(0.10)$ & $<0.001$ \\
\hline$R 5-R 20\left(\mathrm{kPa} \cdot \mathrm{L}^{-1} \cdot \mathrm{s}^{-1}\right)$ & $0.01(0.03)$ & $0.01(0.03)$ & $0.03(0.05)$ & 0.001 \\
\hline$X 5\left(\mathrm{kPa} \cdot \mathrm{L}^{-1} \cdot \mathrm{s}^{-1}\right)$ & $-0.10(0.04)$ & $-0.08(0.03)$ & $-0.11(0.04)$ & $<0.001$ \\
\hline$X 10\left(\mathrm{kPa} \cdot \mathrm{L}^{-1} \cdot \mathrm{s}^{-1}\right)$ & $0.00(0.03)$ & $0.00(0.03)$ & $-0.01(0.04)$ & $<0.001$ \\
\hline$X 15\left(\mathrm{kPa} \cdot \mathrm{L}^{-1} \cdot \mathrm{s}^{-1}\right)$ & $0.04(0.04)$ & $0.04(0.03)$ & $0.04(0.04)$ & 0.856 \\
\hline$X 20\left(\mathrm{kPa} \cdot \mathrm{L}^{-1} \cdot \mathrm{s}^{-1}\right)$ & $0.09(0.04)$ & $0.08(0.03)$ & $0.09(0.05)$ & 0.002 \\
\hline$X 25\left(\mathrm{kPa} \cdot \mathrm{L}^{-1} \cdot \mathrm{s}^{-1}\right)$ & $0.14(0.04)$ & $0.13(0.04)$ & $0.15(0.04)$ & $<0.001$ \\
\hline X35 $\left(\mathrm{kPa} \cdot \mathrm{L}^{-1} \cdot \mathrm{s}^{-1}\right)$ & $0.20(0.06)$ & $0.19(0.05)$ & $0.22(0.07)$ & $<0.001$ \\
\hline$A X\left(\mathrm{kPa} \cdot \mathrm{L}^{-1} \cdot \mathrm{s}^{-1}\right)$ & $0.21(0.16)$ & $0.16(0.10)$ & $0.26(0.19)$ & $<0.001$ \\
\hline fres $(\mathrm{Hz})$ & $10.21(3.40)$ & $9.55(2.89)$ & $10.87(3.76)$ & $<0.001$ \\
\hline
\end{tabular}

Data are presented as median (interquartile range). $\mathrm{P}$ values were derived from the comparison of respiratory impedance between males and females. $Z 5$, total respiratory impedance at $5 \mathrm{~Hz} ; R 5, R 10, R 15, R 20, R 25$ and $R 35$ respectively indicates resistance at $5,10,15,20,25$ and $35 \mathrm{~Hz}$. X5, X10, X15, X20, X25 and X35 respectively indicates reactance at 5, 10, 15, 20, 25 and $35 \mathrm{~Hz}$. IO, impulse oscillometry; AX, low-frequency reactance area; fres, resonant frequency. 
Table S3 Reference equations of IO indices for males

\begin{tabular}{|c|c|c|c|c|c|c|}
\hline IO indices & Components & $\beta$ coefficients $(95 \% \mathrm{Cl})$ & SE of $\beta$ & $P$ & $R^{2}$ & RSD \\
\hline \multirow[t]{3}{*}{$Z 5$} & Intercept & $0.6811(0.5387,0.8236)$ & 0.0723 & $<0.001$ & 0.1877 & 0.0415 \\
\hline & Height & $-0.0032(-0.0041,-0.0023)$ & 0.0005 & $<0.001$ & & \\
\hline & Weight & $0.0019(0.0013,0.0024)$ & 0.0003 & $<0.001$ & & \\
\hline \multirow[t]{3}{*}{$R 5$} & Intercept & $0.6275(0.4850,0.7700)$ & 0.0724 & $<0.001$ & 0.1789 & 0.0420 \\
\hline & Height & $-0.0030(-0.0039,-0.0020)$ & 0.0005 & $<0.001$ & & \\
\hline & Weight & $0.0019(0.0013,0.0025)$ & 0.0003 & $<0.001$ & & \\
\hline \multirow[t]{3}{*}{$R 10$} & Intercept & $0.6361(0.4965,0.7757)$ & 0.0709 & $<0.001$ & 0.2099 & 0.0408 \\
\hline & Height & $-0.0032(-0.0041,-0.0023)$ & 0.0005 & $<0.001$ & & \\
\hline & Weight & $0.0021(0.0015,0.0026)$ & 0.0003 & $<0.001$ & & \\
\hline \multirow[t]{3}{*}{$R 15$} & Intercept & $0.5247(0.3913,0.6581)$ & 0.0678 & $<0.001$ & 0.1224 & 0.0389 \\
\hline & Height & $-0.0023(-0.0031,-0.0014)$ & 0.0004 & $<0.001$ & & \\
\hline & Weight & $0.0014(0.0009,0.0019)$ & 0.0003 & $<0.001$ & & \\
\hline \multirow[t]{4}{*}{$R 20$} & Intercept & $0.5038(0.3445,0.6630)$ & 0.0809 & $<0.001$ & 0.0668 & 0.0401 \\
\hline & Height & $-0.0019(-0.0028,-0.0009)$ & 0.0005 & 0.005 & & \\
\hline & Weight & $0.0010(0.0004,0.0015)$ & 0.0003 & 0.002 & & \\
\hline & Age & $-0.0004(-0.0008,-0.0001)$ & 0.0002 & 0.032 & & \\
\hline \multirow[t]{2}{*}{$R 25$} & Intercept & $0.2103(0.1717,0.2489)$ & 0.0196 & $<0.001$ & 0.0209 & 0.0451 \\
\hline & Weight & $0.0007(0.0001,0.0012)$ & 0.0003 & 0.018 & & \\
\hline$R 35$ & - & - & - & - & - & - \\
\hline \multirow[t]{3}{*}{$R 5-R 20$} & Intercept & $0.2485(0.1780,0.3181)$ & 0.0358 & $<0.001$ & 0.2249 & 0.0205 \\
\hline & Height & $-0.0018(-0.0022,-0.0013)$ & 0.0002 & $<0.001$ & & \\
\hline & Weight & $0.0010(0.0007,0.0013)$ & 0.0001 & $<0.001$ & & \\
\hline \multirow[t]{3}{*}{$x 5$} & Intercept & $-0.3100(-0.3863,-0.2337)$ & 0.0388 & $<0.001$ & 0.1105 & 0.0195 \\
\hline & Height & $0.0013(0.0009,0.0017)$ & 0.0002 & $<0.001$ & & \\
\hline & Age & $0.0002(0.0001,0.0004)$ & 0.0001 & 0.009 & & \\
\hline \multirow[t]{3}{*}{$X 10$} & Intercept & $-0.1620(-0.2166,-0.1074)$ & 0.0277 & $<0.001$ & 0.1956 & 0.0157 \\
\hline & Height & $0.0013(0.0009,0.0016)$ & 0.0002 & $<0.001$ & & \\
\hline & Weight & $-0.0007(-0.0019,-0.0005)$ & 0.0001 & $<0.001$ & & \\
\hline \multirow[t]{4}{*}{$X 15$} & Intercept & $-0.1269(-0.2418,-0.0718)$ & 0.0406 & 0.002 & 0.2575 & 0.0199 \\
\hline & Height & $0.0015(0.0011,0.0021)$ & 0.0002 & $<0.001$ & & \\
\hline & Weight & $-0.0010(-0.0013,-0.0007)$ & 0.0001 & $<0.001$ & & \\
\hline & Age & $-0.0003(-0.0004,-0.0001)$ & 0.0001 & 0.0028 & & \\
\hline \multirow[t]{4}{*}{$X 20$} & Intercept & $-0.1506(-0.2371,-0.0642)$ & 0.044 & $<0.001$ & 0.1556 & 0.0247 \\
\hline & Height & $0.0017(0.0012,0.0023)$ & 0.000 & $<0.001$ & & \\
\hline & Weight & $-0.0009(-0.0012,-0.0005)$ & 0.000 & $<0.001$ & & \\
\hline & Age & $-0.0003(-0.0004,-0.0001)$ & 0.0001 & 0.003 & & \\
\hline \multirow[t]{3}{*}{$x 25$} & Intercept & $0.1789(0.1511,0.2068)$ & 0.0141 & $<0.001$ & 0.0666 & 0.0292 \\
\hline & Weight & $-0.0005(-0.0008,-0.0001)$ & 0.0002 & 0.012 & & \\
\hline & Age & $-0.0005(-0.0007,-0.0002)$ & 0.0001 & 0.001 & & \\
\hline \multirow[t]{3}{*}{$x 35$} & Intercept & $0.3844(0.2495,0.5193)$ & 0.0865 & $<0.001$ & 0.0454 & 0.0382 \\
\hline & Height & $-0.0010(-0.0018,-0.0002)$ & 0.0004 & 0.010 & & \\
\hline & Age & $-0.0005(-0.0008,-0.0002)$ & 0.0002 & 0.001 & & \\
\hline \multirow[t]{3}{*}{ Igfres } & Intercept & $1.9238(1.6487,2.1988)$ & 0.1397 & $<0.001$ & 0.1963 & 0.0801 \\
\hline & Height & $-0.0068(-0.0085,-0.0050)$ & 0.0009 & $<0.001$ & & \\
\hline & Weight & $0.0033(0.0022,0.0044)$ & 0.0006 & $<0.001$ & & \\
\hline \multirow[t]{3}{*}{$\lg A X$} & Intercept & $1.3268(0.5965,2.0572)$ & 0.3709 & 0.004 & 0.1179 & 0.2124 \\
\hline & Height & $-0.0142(-0.0189,-0.0095)$ & 0.0024 & $<0.001$ & & \\
\hline & Weight & $0.0043(0.0014,0.0072)$ & 0.0015 & 0.004 & & \\
\hline
\end{tabular}

IO, impulse oscillometry; $95 \% \mathrm{Cl}, 95 \%$ confidential interval; SE, standard error; $R^{2}$, coefficient of determination; RSD, residual standard deviation. $Z 5$, total respiratory impedance at $5 \mathrm{~Hz} ; R 5, R 10, R 15, R 20, R 25$ and $R 35$ respectively indicates resistance at $5,10,15,20,25$ and $35 \mathrm{~Hz} ; X 5, X 10, X 15, X 20, X 25$ and $X 35$ respectively indicates reactance at $5,10,15,20,25$ and $35 \mathrm{~Hz}$; $\mathrm{AX}$, low-frequency reactance area; fres, resonant frequency. 
Table S4 Reference equations of IO indices for females

\begin{tabular}{|c|c|c|c|c|c|c|}
\hline 10 indices & Components & $\beta$ coefficients (95\% Cl) & SE of $\beta$ & $P$ & $R^{2}$ & RSD \\
\hline \multirow[t]{4}{*}{$Z 5$} & Intercept & $0.9110(0.7378,1.0841)$ & 0.0880 & $<0.001$ & 0.1673 & 0.0493 \\
\hline & Height & $-0.0042(-0.0053,-0.0030)$ & 0.0006 & $<0.001$ & & \\
\hline & Weight & $0.0023(0.0015,0.0031)$ & 0.0004 & $<0.001$ & & \\
\hline & Age & $-0.0008(-0.0013,-0.0003)$ & 0.0002 & 0.001 & & \\
\hline \multirow[t]{4}{*}{ R5 } & Intercept & $0.8103(0.6379,0.9828)$ & 0.0876 & $<0.001$ & 0.1606 & 0.0491 \\
\hline & Height & $-0.0038(-0.0049,-0.0026)$ & 0.0006 & $<0.001$ & & \\
\hline & Weight & $0.0024(0.0016,0.0032)$ & 0.0004 & $<0.001$ & & \\
\hline & Age & $-0.0005(-0.0010,-0.0001)$ & 0.0002 & 0.023 & & \\
\hline \multirow[t]{3}{*}{$R 10$} & Intercept & $0.7013(0.5641,0.8386)$ & 0.0697 & $<0.001$ & 0.1614 & 0.0440 \\
\hline & Height & $-0.0032(-0.0041,-0.0023)$ & 0.0005 & $<0.001$ & & \\
\hline & Weight & $0.0019(0.0012,0.0025)$ & 0.0003 & $<0.001$ & & \\
\hline \multirow[t]{3}{*}{$R 15$} & Intercept & $0.5488(0.4201,0.6775)$ & 0.0654 & $<0.001$ & 0.0593 & 0.0409 \\
\hline & Height & $-0.0019(-0.0027,-0.0010)$ & 0.0004 & $<0.001$ & & \\
\hline & Weight & $0.0007(0.0001,0.0013)$ & 0.0003 & 0.035 & & \\
\hline \multirow[t]{2}{*}{$R 20$} & Intercept & $0.5042(0.3668,0.6415)$ & 0.0698 & $<0.001$ & 0.0282 & 0.0442 \\
\hline & Height & $-0.0013(-0.0021,-0.0004)$ & 0.0004 & 0.004 & & \\
\hline \multirow[t]{2}{*}{ R25 } & Intercept & $0.4928(0.3363,0.6494)$ & 0.0795 & $<0.001$ & 0.0154 & 0.0506 \\
\hline & Height & $-0.0011(-0.0021,-0.0001)$ & 0.0005 & 0.033 & & \\
\hline \multirow[t]{3}{*}{$R 35$} & Intercept & $0.8407(0.6050,1.0764)$ & 0.1197 & $<0.001$ & 0.0700 & 0.0499 \\
\hline & Height & $-0.0025(-0.0039,-0.0011)$ & 0.0007 & 0.001 & & \\
\hline & Age & $-0.0009(-0.0015,-0.0003)$ & 0.0003 & 0.005 & & \\
\hline \multirow[t]{3}{*}{$R 5-R 20$} & Intercept & $0.2360(0.1405,0.3315)$ & 0.0485 & $<0.001$ & 0.1865 & 0.0306 \\
\hline & Height & $-0.0019(-0.0026,-0.0013)$ & 0.0002 & $<0.001$ & & \\
\hline & Weight & $0.0017(0.0013,0.0022)$ & 0.0003 & $<0.001$ & & \\
\hline \multirow[t]{3}{*}{$x 5$} & Intercept & $-0.3605(-0.4406,-0.2805)$ & 0.0407 & $<0.001$ & 0.1233 & 0.0236 \\
\hline & Height & $0.0015(0.0010,0.0019)$ & 0.0002 & $<0.001$ & & \\
\hline & Age & $0.0004(0.0002,0.0006)$ & 0.0001 & 0.006 & & \\
\hline \multirow[t]{3}{*}{$x 10$} & Intercept & $-0.2253(-0.2956,-0.1551)$ & 0.0357 & $<0.001$ & 0.2123 & 0.0225 \\
\hline & Height & $0.0018(0.0013,0.0023)$ & 0.0002 & $<0.001$ & & \\
\hline & Weight & $-0.0012(-0.0015,-0.0009)$ & 0.0002 & $<0.001$ & & \\
\hline \multirow[t]{3}{*}{$x 15$} & Intercept & $-0.1829(-0.2706,-0.0951)$ & 0.0446 & $<0.001$ & 0.2138 & 0.0281 \\
\hline & Height & $0.0020(0.0014,0.0026)$ & 0.0003 & $<0.001$ & & \\
\hline & Weight & $-0.0017(-0.0021,-0.0013)$ & 0.0002 & $<0.001$ & & \\
\hline \multirow[t]{3}{*}{$x 20$} & Intercept & $-0.0534(-0.1579,0.0511)$ & 0.0531 & 0.316 & 0.1140 & 0.0335 \\
\hline & Height & $0.0014(0.0007,0.0021)$ & 0.0004 & $<0.001$ & & \\
\hline & Weight & $-0.0014(-0.0019,-0.0010)$ & 0.0002 & $<0.001$ & & \\
\hline \multirow[t]{3}{*}{$x 25$} & Intercept & $0.2297(0.2013,0.2581)$ & 0.0144 & $<0.001$ & 0.1123 & 0.0358 \\
\hline & Height & $-0.0010(-0.0015,-0.0005)$ & 0.0003 & $<0.001$ & & \\
\hline & Age & $-0.0005(-0.0008,-0.0002)$ & 0.0002 & 0.006 & & \\
\hline \multirow[t]{3}{*}{$x 35$} & Intercept & $0.3214(0.2863,0.3565)$ & 0.0186 & $<0.001$ & 0.1239 & 0.0440 \\
\hline & Weight & $-0.0012(-0.0012,-0.0004)$ & 0.0003 & 0.003 & & \\
\hline & Age & $-0.0008(-0.0018,-0.0005)$ & 0.0002 & $<0.001$ & & \\
\hline \multirow[t]{3}{*}{ Igfres } & Intercept & $1.8261(1.5738,2.0785)$ & 0.1282 & $<0.001$ & 0.2505 & 0.0805 \\
\hline & Height & $-0.0067(-0.0084,-0.0050)$ & 0.0009 & $<0.001$ & & \\
\hline & Weight & $0.0051(0.0039,0.0063)$ & 0.0006 & $<0.001$ & & \\
\hline \multirow[t]{4}{*}{$\lg A X$} & Intercept & $1.6639(0.9404,2.3875)$ & 0.3676 & $<0.001$ & 0.1540 & 0.2037 \\
\hline & Height & $-0.0166(-0.0214,-0.01188)$ & 0.0024 & $<0.001$ & & \\
\hline & Weight & $0.0089(0.0055,0.0122)$ & 0.0017 & $<0.001$ & & \\
\hline & Age & $-0.0029(-0.0049,-0.0009)$ & 0.0010 & 0.004 & & \\
\hline
\end{tabular}

IO, impulse oscillometry; $95 \% \mathrm{Cl}, 95 \%$ confidential interval; SE, standard error; $R^{2}$, coefficient of determination; RSD, residual standard deviation. $Z 5$, total respiratory impedance at $5 \mathrm{~Hz} ; R 5, R 10, R 15, R 20, R 25$ and $R 35$ respectively indicates resistance at $5,10,15,20,25$ and $35 \mathrm{~Hz} ; X 5, X 10, X 15, X 20, X 25$ and $X 35$ respectively indicates reactance at 5, 10, 15, 20, 25 and $35 \mathrm{~Hz}$; AX, low-frequency reactance area; fres, resonant frequency. 

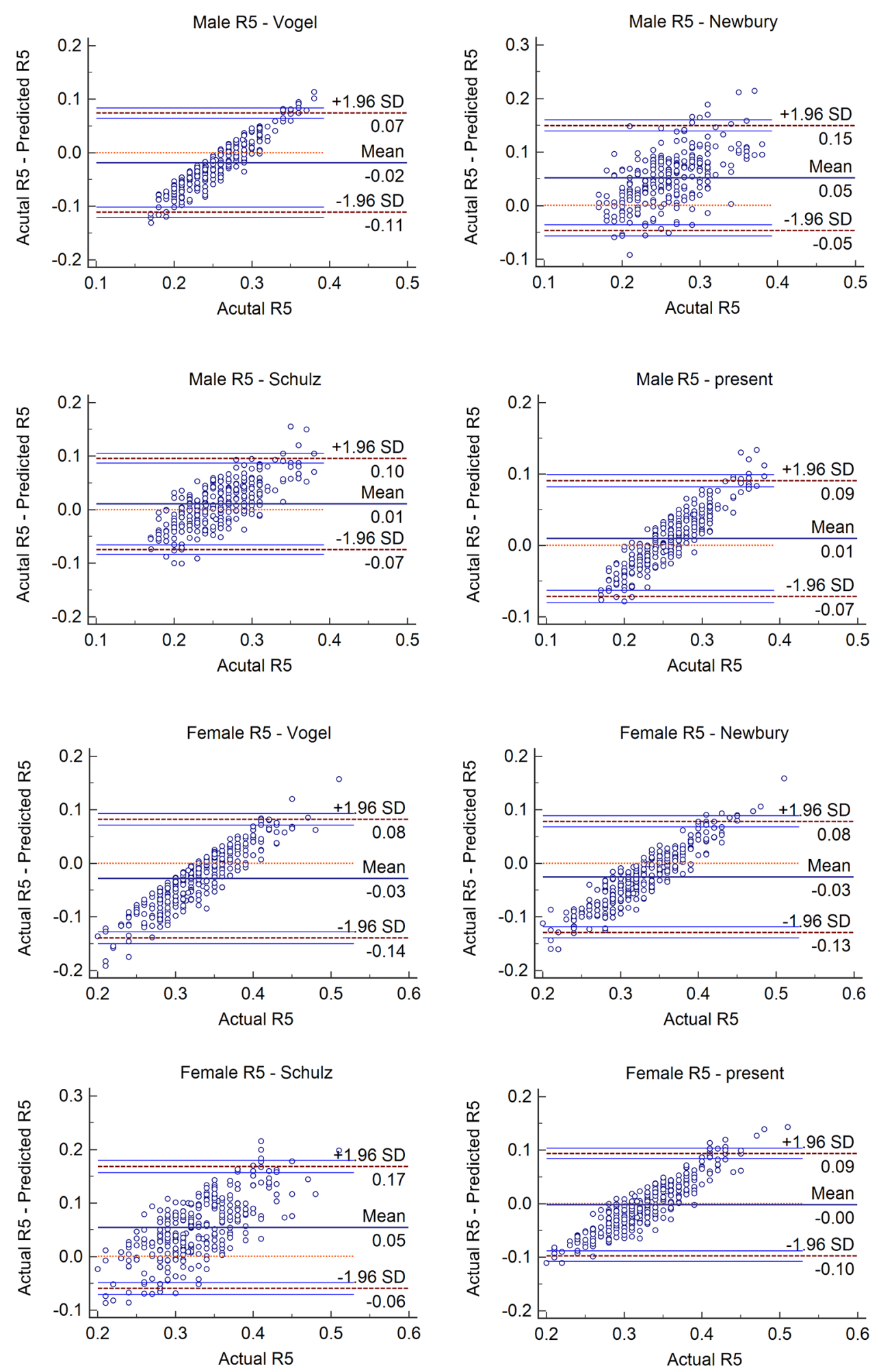

Figure S3 Bland Altman plots for $R 5$. X-axis were the actual values of $R 5$ in healthy subjects of this study, Y-axis were the differences between the actual values and the predicted values. Predicted values were derived by equations of Vogel (9), Newbury (15) and Schulz (18) and the present study. Systematic differences were shown in reference values of Newbury in males, and reference values of Schulz in females. 

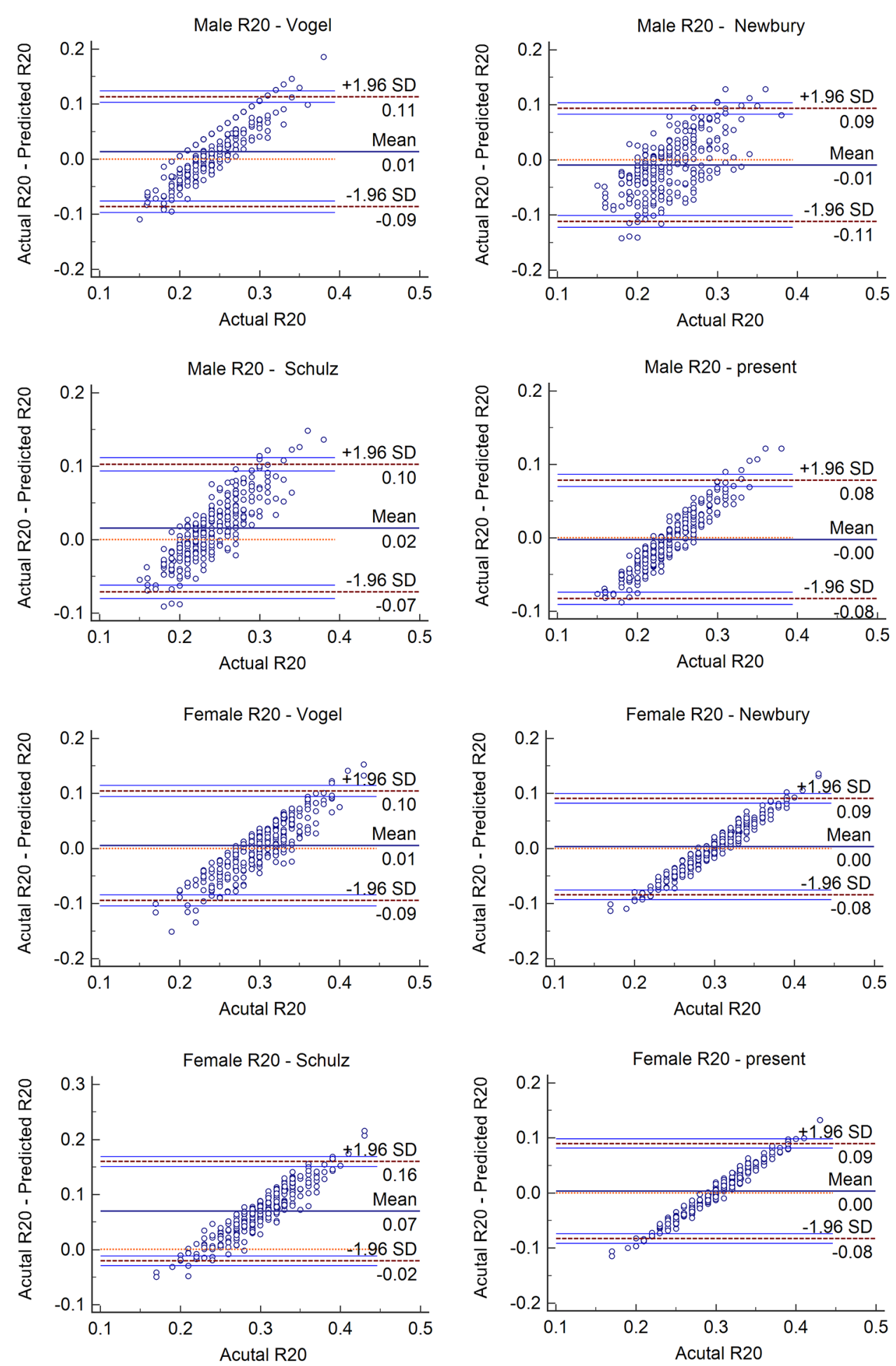

Figure S4 Bland Altman plots for R20. X-axis were the actual values of $R 20$ in healthy subjects of this study, Y-axis were the differences between the actual values and the predicted values. Predicted values were derived by equations of Vogel (9), Newbury (15) and Schulz (18) and the present study. Systematic differences were shown in reference values of Schulz in females. 

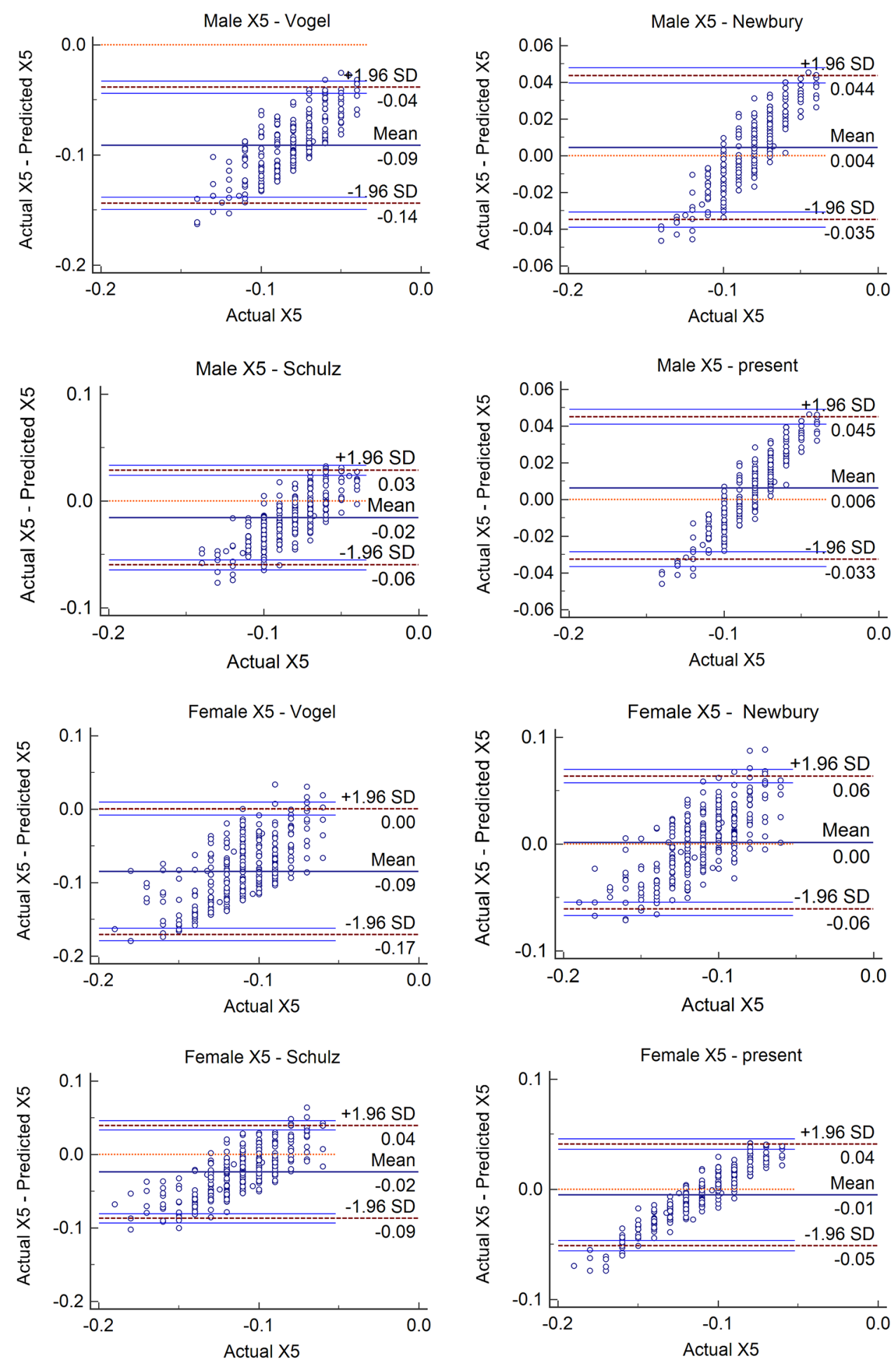

Figure S5 Bland Altman plots for X5. X-axis were the actual values of X5 in healthy subjects of this study, Y-axis were the differences between the actual values and the predicted values. Predicted values were derived by equations of Vogel (9), Newbury (15) and Schulz (18) and the present study. Systematic differences were shown in reference values of Vogel in both males and females. 